\title{
External Whistleblowing in the Public Service: A Necessarily Messy Practice
}

\begin{abstract}
Whistleblowing in the Canadian public service is a complex problem and poses a dilemma: while disclosures can increase organizational effectiveness, they challenge the authority of an organization and cause moral and legal complications. This paper provides an examination of whistleblowing and three reasons why external whistleblowing should not be practiced, namely because of the existence of internal mechanisms, disruptions in ministerial responsibility, and conflicting ideas of loyalty and the public interest. Through this analysis, the paper recommends the strengthening of internal reporting mechanisms to limit external disclosures made in the public service.
\end{abstract}

\footnotetext{
About the Author(s): Clark Jang is a candidate in the Master of Public Administration program at Dalhousie University. He obtained his Bachelor of Journalism (First Class Honours) at the University of King's College in 2013. Clark submitted this paper for an Organizational Design course where he researched whistleblowing in Canada's public service.
} 


\section{Introduction}

In June 2004, Dr. Shiv Chopra and his colleagues Dr. Margaret Haydon and Dr. Gerard Lambert were fired from Health Canada. The trio of scientists publicly blew the whistle on their managers, claiming they were pressured to approve unsafe drugs. Despite the revelations, acknowledgements that the Public Service Integrity Officer mishandled the case, and promises of protection from government retaliation, Drs. Chopra and Haydon were still fighting their dismissals in court in 2013 (FAIR, 2013). The scientists' case is one example of public service whistleblowing where whistleblowers made external disclosures when internal mechanisms did not address their concerns.

Whether or not whistleblowing should be encouraged in Canada's federal public service is a serious problem; it is multi-causal, unstable, and creates unpredictable consequences for those involved. It creates tension-on one hand, whistleblower information could improve organizational effectiveness; on the other, it challenges the authority structure of the organization (Near \& Miceli, 1985).

Furthermore, complications could arise depending on whether the whistleblower uses disclosure internally or externally to the organization. And while both internal and external avenues have been employed to expose dubious behaviour by public officials who claim to operate in the public interest, this essay argues that external whistleblowing should not be encouraged in the public service for three reasons: the existence of internal reporting structures, a disruption of ministerial responsibility, and the breach of loyalty and public sector values.

The argument proceeds by establishing a functional definition of whistleblowing, examining the features of whistleblowers, and making the distinction between internal and external whistleblowing. Next, the argument will examine existing internal structures for whistleblowers, the disruption of ministerial responsibility, and the complications that arise when public service values are pitted against the duty of loyalty owed to one's employer. Finally, a recommendation will be made to limit the number of disclosures in the public service, namely, to strengthen internal reporting structures.

\section{Whistleblowing Defined}

Whistleblowing has been described as a "morally ambiguous" practice (Thomas, 2005; Review and Implementation Committee, 2001). H.L. Laframboise, a former Assistant Deputy Minister, famously described whistleblowers whose disclosures harm their community or peer groups as "vile wretches," while "those who blow the whistle on events and conditions deemed by the community or peer group to be so 
abhorrent as to justify their being reported" as "public heroes" (1991, p.1). Ambiguity arises out of subjective judgments placed on the actions and motivations of whistleblowers and can create legal, organizational, personal and ethical dilemmas for those who blow the whistle (Thomas, 2005). Due to the nebulous nature of whistleblowing, this essay will use Near and Miceli's ubiquitous and widely-accepted definition, which is "the disclosure by organization members (former or current) of illegal, immoral or illegitimate practices under the control of their employers, to persons or organizations that may be able to effect action" (1985, p.4). By extension, a whistleblower is the agent who makes the disclosure of information.

There are several unique features of a whistleblower. First, they make disclosures in the public interest; their complaints are not personal vendettas against their employer or fellow employees (Young, 2011). The altruistic nature of the practice is evident from the risk of reprisal - physical, psychological, or economic - assumed by the whistleblower. Other characteristics include: belonging to the organization in question, lacking authority to rectify the problem, a possible occupation of a role where the disclosures are encouraged (such as an internal auditor), and the possibility of remaining anonymous (Near \& Miceli, 1985).

A distinction must also be made between internal and external whistleblowing. Internal whistleblowing is when a whistleblower uses mechanisms "outside the regular chain of command," but still within the bureaucratic realm (Kaptein, 2010, p. 515). For example, Canada Post has a whistleblowing hotline employees can call to report a wrongdoing, circumventing the traditional chain of authority from employee to manager (Canada Post, 2014). External whistleblowing is when a whistleblower uses means external to the bureaucracy - such as the media, law enforcement, or a professional organization - to disclose an alleged malpractice.

\section{Existing Mechanisms}

Mechanisms and resources exist within the federal public service for employees to report alleged wrongdoings. In 2007, the Office of the Public Sector Integrity Commissioner was created to provide information and assistance to public servants who make or may make disclosures, and act as a conduit between whistleblowers and the bureaucracy. As well, organizations may employ other internal resources for employees to consult, such as internal disclosure officers, union representatives or ethics officers (PSIC, 2013). Furthermore, safeguards in the form of legislation exist, such as the Public Servants Disclosure Protection Act (PSDPA) and the Criminal Code. There are even provincial regulations, such as the Public Service of Ontario Act (2006), which 
provide regional protections to whistleblowers. Thus, if a grievance was to be reported or a whistle was to be blown, it should be done through the various internal avenues that were established for the sole purpose of reporting wrongdoings. The encouragement of external whistleblowing would make prescribed internal mechanisms - if they were not working to the satisfaction of the whistleblower optional, superfluous, and self-defeating.

External disclosures can also lead to public embarrassment of an organization, fines, and litigation (Berry, 2004). But external disclosures expose more than wrongdoings, they also expose an organization unable to rectify the wrongdoing internally (Kaptein, 2011). This can lead to negative public perceptions, deference towards the government, and distrust of the service being offered. For example, after the whistle was blown on the Sponsorship Scandal, an opinion poll showed that the Liberal Party collapsed from 44 percent of decided voters in July 2003 to 35 percent in April 2004. According to the same poll, 40 percent of respondents said their impression of Prime Minister Paul Martin had suffered since the scandal (Canadian Press, 2004). Even though external avenues may draw wider public attention, their use can send negative policy signals to the public and throughout the bureaucracy, with implications for the efficiency and efficacy of the organization.

\section{Ministerial Responsibility}

One of the fundamental tenets of responsible government in Canada is ministerial responsibility. Parliament transfers ministerial responsibility to ministers through statues that outline powers, duties, and functions for which a minister is individually accountable (Government of Canada, 2011). This means ministers "are responsible for all that is done by themselves directly or in their name by their subordinates and they are thereby accountable for the exercise of their authority by themselves and others they so authorize, explicitly or implicitly" (Aucoin, n.d., p.108). Accountability, in other words, flows up the chain of command from the subordinates to the minister, as work and responsibilities are delegated downwards. Therefore, the burden of departmental accountability that falls on the minister means the problems are ultimately his or her own, and not the public servants' under the minister's purview. Bordeleau (2011) argues external disclosures by whistleblowers would therefore disrupt the "feedback loop of accountability" by bypassing the minister when problems arise (p. 198). Taken further, an external disclosure would circumvent internal mechanisms in place to allow the minister to identify and rectify the problem. The flow of information is paramount if a minister is to remain transparent to the public and accountable to Parliament. By withholding information, public servants cloud governmental transparency, impeding 
ministerial accountability and, by extension, democratic governance. This could send negative policy signals to the public and throughout the bureaucracy, and also violates public service values.

\section{Public Sector Values and Loyalty}

In July 2013, Sylvie Therrien, an Employment Insurance (EI) investigator with Service Canada, was suspended without pay after leaking documents to the media alleging the government set annual $\$ 485,000$ quotas for investigators to recover in $\mathrm{El}$ fraud (Kane, 2013). Ms. Therrien claims her initial attempts at making internal disclosures were dismissed. And although Ms. Therrien claimed to be acting in the public interest, her actions violated key principles of Canada's public service.

As a professional and non-partisan public service, Canadian public sector employees have core values which guide their work, including: respect for democracy, respect for people, integrity, stewardship and excellence (Treasury Board of Canada Secretariat, 2011). In the context of external whistleblowing, these guiding principles can cause moral and legal conflicts. For example, external disclosures can cause a disruption of ministerial responsibility, violating the mutual respect and trust shared by ministers and public servants. Public servants must recognize that "elected officials are accountable to Parliament, and ultimately to the Canadian people, and that a non-partisan public sector is essential to [Canada's] democratic system" (Treasury Board of Canada Secretariat, 2011). External disclosures thereby restrict ministers' access to information regarding organizational problems, disrupting the aforementioned feedback loop of accountability and obscuring transparency.

Furthermore, employees and also employers have a duty of loyalty under law (Cohen-Lyon \& Morley, 2012). For example, Ms. Therrien - by exposing her employer's wrongdoing externally - violated the duty of loyalty between herself and the government. Although whistleblower provisions are laid out in the PSDPA and the Criminal Code, there are limitations on the extent of protection whistleblowers face. As laid out in the PSDPA, external disclosures can be made if an act, event, or condition:" (a) constitutes a serious offence under an Act of Parliament or of the legislature of a province; or(b) constitutes an imminent risk of a substantial and specific danger to the life, health and safety of persons, or to the environment" (PSDPA, 2005).

While the presence of quotas may seem like an egregious violation, under the PSDPA, it does not fulfill the criteria warranting an external disclosure. Simply, whistleblowing in certain circumstances can be against the law: "public servants must give priority to the processes, procedures and provisions found in the laws governing 
the provision of particular public services..." (Aucoin, n.d., p.24). While the whistleblower may have altruistic intentions, potentially criminal acts should not be encouraged in the public service as it can delegitimize the authority placed in government through democratic processes. However, this ambiguity leaves much to be desired by whistleblowers and leads to moral and legal obstacles.

\section{Complications}

External disclosures should only be made once all other internal mechanisms are exhausted, as any action before that raises the question of whether or not the whistleblower is acting in good faith (Young, 2011). Whistleblowing, however, can be complicated by the scale and complexity of the disclosure. For example, after National Security Agency contractor Edward Snowden blew the whistle on the United States' extensive spying regime, the government engaged in extensive foreign and domestic damage control to dispel Snowden's espionage allegations. Snowden, for his part, said he blew the whistle externally because he believed an internal disclosure would have "discredited and ruined" him, and his warnings would be "buried forever" (Pilkington, 2013). Although Snowden's revelations are situated in an American context, it begs the question: are Canadian structures and safeguards comprehensive enough to discourage the use of external avenues?

One key difficulty in examining whistleblowing is identifying the parameters of a wrongdoing. This adds to the moral ambiguity of the practice. The PSDPA identifies six criteria which constitute a wrongdoing, including: (a) violation of federal or provincial laws or regulations; (b) misusing public funds or assets; (c) gross mismanagement in the public sector; (d) doing something or failing to do something that creates a significant and specific danger to the health, safety or life of persons or to the environment; (e) seriously breaching the Values and Ethics Code for the Public Sector and; (f) knowingly directing or counseling a person to commit a serious wrongdoing (Government of Canada, 2005). These criteria, however explanatory, remain relativistic and non-explicit in their definitions of a wrongdoing. What constitutes gross mismanagement or a serious breach could differ between government organizations; what constitutes a serious offense or imminent threat under the PSDPA is similarly ambiguous. This could pose a hazard for whistleblowers as the boundaries between legality, morality, and legitimacy become blurred. Without a definitive method to determine whether rules or values and loyalty or public interest takes precedence, it leaves much to be desired by whistleblowers who lack prescriptive and explicit processes when internal avenues fail. 
Complications may also arise after internal mechanisms are exhausted. Studies have shown that whistleblowers who make external disclosures often exhaust internal mechanisms, or feel that internal structures will not be receptive to their information (Dworkin \& Baucus, 1998). This creates a gray area where external disclosures are not permitted by law, but organizational structures are unreceptive to the alleged wrongdoing. Simply, the whistleblower is caught between the convoluted ideas of loyalty to the employer, and the public interest.

Finally, there is empirical evidence to support the notion that external whistleblowing has greater effectiveness in initiating organizational change (Dworkin \& Baucus, 1998). The greater effectiveness of external avenues could pose a threat to established mechanisms, and lead to the disuse of reporting structures, disruptions in ministerial responsibility, and conflicts of public sector values. Until there is meaningful discourse and organizational structure changes to resolve the aforementioned complications, it would be irresponsible for a morally ambiguous practice like whistleblowing to be encouraged in the public service given its propensity to jeopardize careers and livelihoods. As such, internal mechanisms should be strengthened to prescribe precise and effective procedures for dealing with wrongdoings and limiting external disclosures.

\section{Strengthening and Renewal}

Public sector organizations should strengthen reporting mechanisms and safeguards for internal disclosures to discourage external whistleblowing. Comprehensive internal reporting structures can limit the number of external disclosures, and are consistent with the government's commitment to public sector renewal.

There are numerous steps organizations can take to implement robust whistleblowing regimes that extend beyond simple policies. In its G20 Anti-Corruption Action Plan for the Protection of Whistleblowers, the Organization for Economic Cooperation and Development (OECD) outlines seven priorities for the design and implementation of whistleblower safeguards, including: (a) comprehensive and clear legislation; (b) effective institutional frameworks and clear procedures and channels; (c) clearly defined protected disclosures and persons afforded protection; (d) clearly defined retaliatory actions; (e) clearly outlined remedies and sanctions; (f) regular awareness-raising and; (g) periodic evaluation of whistleblower protections (2011). These broad measures were designed "taking into account the diversity of legal 
systems among G20 countries" - including Canada - and can be adapted to meet countries' specific needs (OECD, 2011, p.30).

Although Canada possesses legislation and reporting mechanisms for federal public servants consistent with the OECD recommendations - such as the PSDPA and the Office of the Public Sector Integrity Commissioner - there is a lack of homogeneity and commitment across government at the organizational level. For example, public servants "involved in national security cannot complain to the Public Service Integrity Commissioner" (CleanBizGov, 2012). This includes employees of the Canadian Forces, the Canadian Security Intelligence Service and the Communications Security Establishment Canada, which can leave them distressed, vulnerable to reprisal, or seeking alternative means of disclosure. Despite overarching protection at the federal level, a robust whistleblowing culture needs to be implemented at the organizational level-a strategy in line with public sector renewal.

In his $17^{\text {th }}$ Annual Report to the Prime Minister on the Public Service of Canada, Mr. Wayne Wouters, Clerk of the Privy Council Office, notes public sector renewal "is an ongoing, overarching strategy aimed at equipping public servants to better serve the Government, using new tools and approaches but fulfilling the same mission of excellence in service to Canadians" (2010, p.1). Public sector renewal has been a priority outlined in Mr. Wouters' annual reports since 2010, and extends to all corners of Canada's public service. It includes government-wide initiatives from modernizing payment systems to individual organizational projects, such as the Department of National Defence's Return to Work Program (Wouters, 2013). A government-wide reporting regime is compatible with the idea of public sector renewal as it could help public employees serve the government more effectively by reducing incidents of questionable behaviour. However, whistleblowing culture still needs to be fostered at the organizational level.

The creation and maintenance of whistleblowing culture at the organizational level - like renewal - needs to be a management priority. In line with OECD best practices, managers should receive training "to receive reports, and to recognize and prevent occurrences of discriminatory and disciplinary action taken against whistleblowers" (2011, p.33). Furthermore, renewal, in whatever form it takes, needs to be driven by deputy ministers (Wouters, 2010). There needs to be vertical and horizontal engagement of employees to facilitate dialogue and the implementation of whistleblowing culture. Employees should feel free to blow the whistle if they encounter a wrongdoing without fear of reprisal. 
Organizations should also raise awareness about their efforts to promote internal whistleblowing (OECD, 2011). This can include regular communication to employees about policies and resources, ethical behavior and tolerance of good faith disclosures. Communication can occur through e-mails, memos, presentations or individual or departmental meetings.

Finally, regular assessments should be conducted to determine the efficacy of the whistleblowing regime (OECD, 2011). This includes adjustment - where necessary to ensure whistleblowing policies and procedures evolve with the organization and the needs of the employees. Simply tolerating internal whistleblowing is insufficient to prevent external disclosures. There needs to be an organizational culture shift in which whistleblowing can occur without fear of reprisal, as the information could be invaluable in fulfilling the public service's role to government and Canadians. 


\section{References}

Aucoin, P. (n.d.). Organizational design course reader. Dalhousie University. Halifax, Nova Scotia.

Berry, B. (2004). Organizational culture: A framework and strategies for facilitating employee whistle-blowing. Employee Responsibilities and Rights Journal, 16(1), 1-11. Retrieved from http://link.springer.com/article/10.1023\%2FB\%3AERRJ.0000017516.40437.bl

Bordeleau, C. (2011). The case against whistleblowing. In Leone, R. P., \& Ohemeng, F. L. K. (Eds.), Approaching Public Administration: Core Debates and Emerging Issues (p. 196-206). Toronto, Ontario: Emond Montgomery Publications Ltd.

Canada Post. (2014). Whistleblowing. Canada Post. Retrieved from http://www.canadapost.ca/cpo/mc/aboutus/corporate/whistleblowing.jsf

Canadian Press. (2004, Apr. 13). Canadian voters weren't ready to look past sponsorship scandal: Poll. Canadian Press. Retrieved from http://ezproxy.library.dal.ca/login?url=http://search.proquest.com/docview/ 357263298 ? accountid $=10406$

CleanGovBiz. (2012). Whistleblower protection: encouraging reporting. Organization for Economic Co-operating and Development. Retrieved from http://www.oecd.org/cleangovbiz/toolkit/50042935.pdf.

Cohen-Lyons, J., \& Morley, H. (2012). Whistleblowing in the public sector: A balance of rights and interests. Public Sector Digest. Retrieved from http://www.hicksmorley.com/images/Hicks_Morley.pdf

FAIR. (2013, Nov. 3). Dr. Shiv Chopra [Video file]. Retrieved from http://www.youtube.com/watch?v=jTQumihlcfY

Government of Canada. (2011). Accountable government: A guide for ministers and ministers of state. Government of Canada. Retrieved from http://www.pm.gc.ca/grfx/docs/guidemin_e.pdf 
Kane, L. (2013, July 22). Suspension of El whistleblower sets dangerous precedent, critics say. The Toronto Star. Retrieved from http://www.thestar.com/news/canada/2013/07/22/suspension_of_ei_whistle blower_sets_dangerous_precedent_critics_say.html

Kaptein, M. (201 1). From inaction to external whistleblowing: The influence of the ethical culture of organizations on employee responses to observed wrongdoing. Journal of Business Ethics, 98(3), 513-530. Retrieved from http://www.jstor.org/stable/41476147

Laframboise, H.L. (1991). Vile wretches and public heroes: The ethics of whistleblowing in government. Canadian Public Administration, 34(1), 73-77. Retrieved from http://onlinelibrary.wiley.com/doi/10.1111/j.17547121.1991.tb01438.x/abstract

Near, J. P., \& Miceli, M. P. (1985). Organizational dissidence: The case of whistleblowing. Journal of Business Ethics, 16(1), 1-16. Retrieved from http:// www.jstor.org.ezproxy.library.dal.ca/stable/pdfplus/25071466.pdf? acceptTC=true\&acceptTC=true\&.jpdConfirm=true

Organization for Economic Co-Operation and Development. (2011). Protection of whistleblowers: Study on whistleblower protection frameworks, compendium of best practices and guiding principles for legislation. Retrieved from http://www.oecd.org/g20/topics/anti-corruption/48972967.pdf

Pilkington, E. (2013, Oct. 18). Edward Snowden: US would have buried NSA warnings forever. The Guardian. Retrieved from http://www.theguardian.com/world/2013/oct/18/edwardsnowden-us-would-have-buried-nsa-warnings-forever

Public Servants Disclosure Protection Act. (2005). Retrieved from the Justice Laws website: http://laws-lois.justice.gc.ca/eng/acts/P-31.9/

Public Sector Integrity Commissioner. (2013). Decision-making guide. Government of Canada. Retrived from http://www.psic.gc.ca/eng/content/decisionmaking-guide 
Review and Implementation Committee. (2001). The duty of loyalty versus the duty to inform. In Report of the review and implementation committee for the report of the Manitoba pediatric cardiac surgery inquest (Chapter Six). Retrieved from http://www.gov.mb.ca/health/documents/cardiac/07prc6.pdf

Thomas, P. G. (2005). Debating a whistle-blower protection act for employees of the Government of Canada. Canadian Public Administration, 48(2), 147-184. Retrieved from http://onlinelibrary.wiley.com/doi/10.1111/j.1754-7121.2005.tb02186.x/citedby

Treasury Board of Canada Secretariat. (2011). Values and ethics code for the public Sector. Government of Canada. Retrieved from https://www.tbssct.gc.ca/pol/doc-eng.aspx?id=25049\&section=text\#cha4

Wouters, W. G. (2010). Seventeenth annual report to the Prime Minister on the public service of Canada. Government of Canada. Retrieved from http://www.clerk.gc.ca/eng/feature.asp?pageld=231

Wouters, W. G. (2013). Twentieth annual report to the Prime Minister on the public service of Canada. Government of Canada. Retrieved from http://www.clerk.gc.ca/eng/feature.asp?pageld=319

Young, S. (2011). In support of whistleblowing. In Leone, R. P., \& Ohemeng, F. L. K. (Eds.), Approaching public administration: Core debates and emerging issues (p. 185-195). Toronto, Canada: Emond Montgomery Publications. 